\title{
Distribution and Abundance of Bacteria in the Gut of a Soil-feeding Termite Procubitermes aburiensis (Termitidae, Termitinae)
}

\author{
By D. E. BIGNELL, H. OSKARSSON AND J. M. ANDERSON* \\ Department of Biological Sciences, Wolfson Ecology Laboratory, University of Exeter, \\ Exeter EX4 4PS
}

(Received 15 June 1979; revised 19 September 1979)

\begin{abstract}
The alimentary canal of a representative species of soil-feeding termite was examined for associations with bacteria. Enumerations made in the principal regions of the intestine by direct observation and expressed for comparative purposes as total microbial standing crop showed a net three- to fourfold increase between the foregut (crop) and rectum. Filamentous organisms, putatively actinomycetes, contributed significantly to the flora in most regions of the gut and were more abundant, relative to non-filamentous forms, than in freshly ingested soil. Transmission and scanning electron microscopy of the gut wall showed that the actinomycetes formed novel associations with the host in the mesenteron, mixed segment and colon. Non-filamentous organisms, chiefiy rods, colonized the walls of the first proctodaeal segment and the colon, in addition to filaments, and were present in large numbers in the contents of the third proctodaeal segment.
\end{abstract}

\section{INTRODUCTION}

It has long been recognized that gut microbiota play a significant role in the digestive processes of termites (Grassé \& Noirot, 1959; Brooks, 1963; Noirot \& Noirot-Timothée, 1969; Honigberg, 1970). However, detailed analyses of these symbiotic relationships have been largely confined to the relatively small group of species representing the primitive families (Lower Termites) while the abundant, diverse and ecologically important family of Termitidae (Higher Termites) has been comparatively little studied.

The Lower Termites are largely xylophagous. A primary mutualism exists with intestinal flagellates which digest cellulose anaerobically to form a range of organic acids, some of which are absorbed by the host (Hungate, 1955; Honigberg, 1970). Many bacteria are also present in the gut, the majority free or associated with the wall (Breznak \& Pankratz, 1977), others forming a secondary symbiosis with the flagellates (Bloodgood et al., 1974). The role of bacteria in the digestive processes of Lower Termites is controversial, but evidence of significant nitrogen fixation in both gut isolates and intact termites has been recorded (Breznak et al., 1973; Potrikus \& Breznak, 1977).

The Higher Termites have undergone extensive trophic diversification and utilize not only the majority of plant resource types, including wood, but also soil organic matter (Lee \& Wood, 1971). Their symbiotic associations have been examined in wood-feeding Macrotermitinae (Martin \& Martin, 1978; Rohrmann, 1978) and Nasutitermitinae (Eutick et al., 1978), but little is known about the biology of the soil-feeders (Apicotermitinae, most Termitinae and some Nasutitermitinae) although they represent about $60 \%$ of all Higher Termite species. Because of the complex organization of the gut (Grassé \& Noirot, 1959; 
Noirot \& Kovoor, 1958) it is assumed that bacteria play a primary role in digestive processes. Protozoa are not thought to contribute significantly to the nutrition of Higher Termites (Honigberg, 1970).

Soil-feeding termites are particularly abundant in the rain forests of West Africa and South America where populations in excess of $3000 \mathrm{~m}^{-2}$ have been recorded (T. G. Wood \& J. M. Anderson, unpublished results). Large amounts of soil are ingested, estimated, for example, at $2.76 \mathrm{~g}$ ( $\mathrm{g}$ termite) $)^{-1} \mathrm{~d}^{-1}$ for a species of Cubitermes (Wood, 1976), and faecal material is incorporated into mounds or gallery walls. Although largely undetermined at present, this activity must have considerable effects on soil structure, physical and chemical processes and on organic matter decomposition. Of particular interest are the possible effects of soil-feeders on bacterial and fungal populations. It is not known, for example, whether passage of soil through the gut stimulates or inhibits microbial activity in a similar manner to temperate soil arthropods (Wood, 1976; Hanlon \& Anderson, 1980; Anderson \& Bignell, 1980). The nature of the organic resources utilized by soil-feeding termites is also unclear.

Gut content analysis supported by particle size, organic carbon and mineral analyses of mound material in the African humivore Procubitermes aburiensis failed to provide any evidence that the cellular remains of higher plants were selected at the expense of other soil fractions (J. M. Anderson \& T. G. Wood, unpublished results). It is therefore probable that organic resources are provided either by microbial tissues or by humus or by both of these.

In this paper, we report an examination of the gut flora of $P$. arburiensis, the first such investigation of any humivorous termite. The primary approach was ecological: the determination of changes in total microbial populations occurring during the passage of ingested soil through the alimentary canal. This was supported by an electron microscopical examination of the gut wall designed to furnish morphological evidence of symbiotic associations and identify regions where these occur. Our results demonstrate significant changes in the abundance and composition of bacterial populations within the intestine and show that prominent associated organisms are fine filaments, probably actinomycetes.

\section{METHODS}

Procubitermes aburiensis Sjöstedt (Isoptera, Termitidae, Termitinae) mounds were collected in an alluvial secondary forest at Rabba, Nigeria, and air-freighted to the U.K. In the laboratory, mounds were partially buried in bins of remoistened, air-dried woodland soil and maintained at $25^{\circ} \mathrm{C}$ and $100 \%$ relative humidity. Worker-caste termites were sampled from soil adjacent to the mound and occasionally from the mound itself. Guts were dissected using aseptic procedures but prior surface sterilization was found to be unnecessary for quantitative work.

The gut was separated into nine regions (Fig. 1): crop; mesenteron; mixed segment; proctodaeal segment 1 (P1); proctodaeal segment $3(\mathrm{P} 3)$; caecum; proctodaeal segment 4 anterior $(\mathrm{P} 4 \mathrm{a})$; proctodaeal segment 4 posterior (P4b); rectum (P5). To prevent spillage of its contents the caecum was ligatured with fine surgical thread before being separated from the P3. At each determination the guts of 20 insects were dissected and the individual regions were pooled in separate $1 \mathrm{ml}$ portions of $0.1 \%(\mathrm{w} / \mathrm{v})$ peptone water in a McCartney bottle. The samples were vigorously shaken for 5 min to break up the gut wall and disperse its contents. For direct observation of micro-organisms, agar films were prepared from undiluted homogenates by a modification of the method of Jones \& Mollison (1948) and stained with phenolic aniline blue. Dilution plates were prepared with Oxoid nutrient agar and incubated aerobically for $14 \mathrm{~d}$ at $25^{\circ} \mathrm{C}$ (Parkinson et al., 1971). Additional plates were made with nutrient agar pre-reduced by the addition of sodium thioglycollate $(0.5 \%, \mathrm{w} / \mathrm{v})$ and incubated anaerobically in a BBL GasPak system jar. Homogenates of the mesenteron and mixed segment, $\mathrm{P} 3$ and caecum, $\mathrm{P} 4$ and $\mathrm{P} 5$, respectively, were pooled for plating.

Bacterial standing crops and colony-forming units were calculated per g dry weight of gut and contents. The dry weights were determined by passing a sample of the homogenate through a tared Millipore membrane (pore diameter $0.45 \mu \mathrm{m}$ ) and drying the membrane to constant weight in vacuo before reweighing. In agar films a distinction was made between non-filamentous cells, which were counted, and filamentous forms, the total length of which was determined by the intersect method of Olsen (1950). These data were converted 


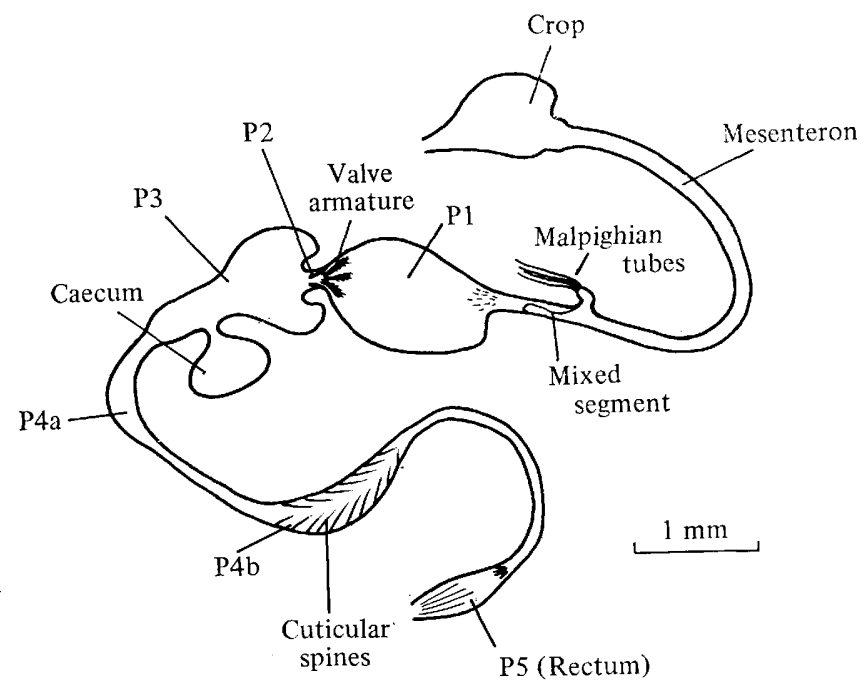

Fig. 1. General morphology of the alimentary canal.

to standing crop as described by Parkinson et al. (1971), assuming for non-filamentous bacterial cells a volume of $1 \mu \mathrm{m}^{3}$ and relative density of 1.5 , and for filaments a mean diameter of $0.5 \mu \mathrm{m}$ and a relative density of $1 \cdot 5$. Statistical comparisons between different regions of the gut were made with the nonparametric Kruskal-Wallis and Mann-Whitney U tests (Sokal \& Rohlf, 1969).

Ignition weight losses (at $400{ }^{\circ} \mathrm{C}$ ) were determined for each region of the alimentary canal from a pooled sample of 40 guts. The results showed that the contribution of organic material to dry weight (i.e. gut wall, microbial tissue and soil organic matter) did not vary sufficiently to affect standing crop comparisons significantly.

For scanning electron microscopy, guts were dissected in buffered Ringer's solution ( $\mathrm{pH} 7 \cdot 2$ ), opened by longitudinal incisions and agitated briefly in the solution to remove loose mineral debris. They were then transferred to a solution of $2 \cdot 5 \%(\mathrm{v} / \mathrm{v})$ glutaraldehyde in $0 \cdot 1 \mathrm{M}$-phosphate buffer $(\mathrm{pH} 7 \cdot 2)$ and fixed for $1 \mathrm{~h}$. Specimens were dehydrated in acetone, critical point dried and coated with gold prior to viewing.

For transmission electron microscopy (mesenteron only), tissues were fixed in a mixture of $1.5 \%(\mathrm{v} / \mathrm{v})$ acrolein and $1.5 \%(\mathrm{v} / \mathrm{v})$ glutaraldehyde without removal of mineral materials and postfixed in $1 \%(\mathrm{w} / \mathrm{v})$ $\mathrm{OsO}_{4}$. Blocks were stained with uranyl acetate and sectioned with a diamond knife.

\section{RESULTS}

\section{Gross morphology of the gut}

In soil-feeding termites there is considerable development and specialization of the hindgut, which distends the abdominal cavity (Noirot \& Noirot-Timothée, 1969). Since the literature contains no account of gut morphology in Procubitermes sufficiently detailed to show the diversity of microbial habitats to be found within it, a brief description is given here (see Fig. 1).

Following the foregut (largely crop) and mesenteron the hindgut begins where the Malpighian tubules join the alimentary canal. There follows immediately a mixed segment in which the intestinal lumen is limited on one side by proctodaeal tissue and on the other by a posterior extension of the mesenteron. In many Higher Termites this unique composite region of the gut is associated with the presence of symbionts (Grassé \& Noirot, 1959; Kovoor, 1959, 1969), but no information has been available to date on soil-feeders, including Procubitermes. After the mixed segment come five proctodaeal segments. The first of these (P1) is a large dilation containing about half the soil present in the entire alimentary canal, 


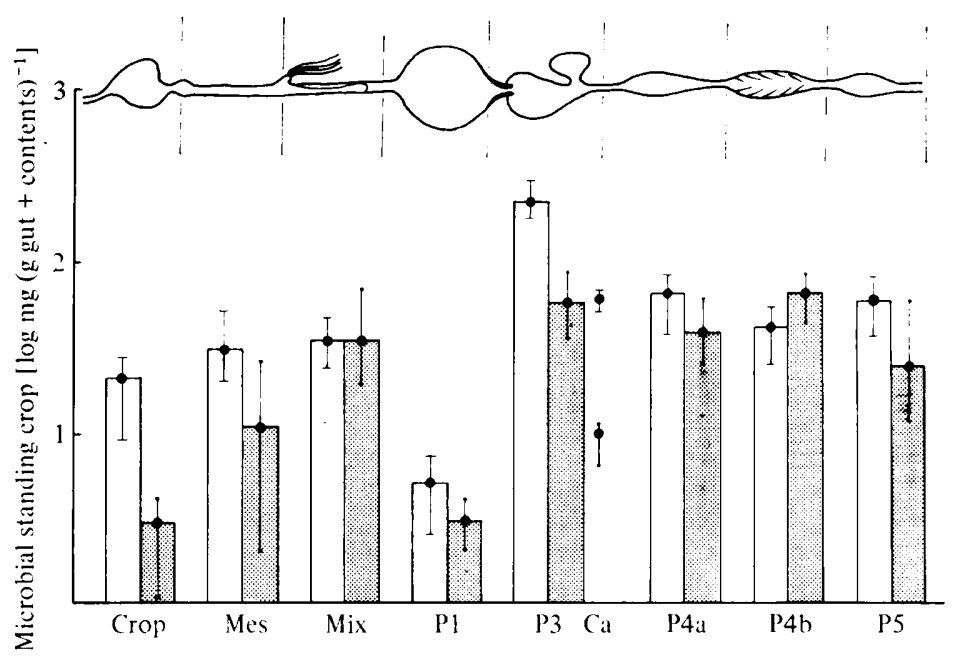

Fig. 2. Standing crops of non-filamentous (open bars) and filamentous (shaded bars) microorganisms in each region of the gut, determined by direct observation. The means and ranges of eight observations are shown. Mes, mesenteron; Mix, mixed segment; $\mathrm{Ca}$, caecum. The gut is represented diagrammatically in the unravelled state and is not to scale.

followed by a short segment (P2) containing the enteric valve, a sclerotized muscular funnel invaginated into the hindgut paunch (P3) immediately posterior to the valve. The P3 itself gives rise to a lateral caecum which is periodically expanded and contracted by the entry of soil from the intestine and its subsequent discharge back into the gut. The colon (P4) contains two muscular dilations (designated $\mathrm{P} 4 \mathrm{a}$ and $\mathrm{P} 4 \mathrm{~b}$, respectively), separated from one another and from the P3 by short strongly muscular connections. A notable feature of the $\mathrm{P} 4 \mathrm{~b}$ is the elaboration of numerous greatly elongated spines from the cuticle lining the gut wall. With an average length of $200 \mu \mathrm{m}$, the spines form a matrix which fills the gut lumen and provides attachment sites for the numerous microbial filaments prominent amongst the hindgut flora (see below). The hindgut terminates at the rectum (P5). The entire gut is kept full of soil which cannot be displaced by inanition. The transit time is 36 to $48 \mathrm{~h}$.

\section{Bacterial standing crops and colony-forming units}

Standing crops of bacteria determined by direct observation are shown in Fig. 2. Since the ingestion of soil is a selective process normally occurring underground, accurate enumerations of preingested soil could not be made. Consequently, determinations were confined to the alimentary canal on the assumption that the crop contents approximated closely to the soil fractions ingested.

Non-filamentous cells were significantly less numerous in the P1 than in all other regions of the gut $(P<0.001)$, the average reduction being about one order of magnitude. The P3 showed the highest standing crops, significantly greater than all other regions $(P<0 \cdot 001)$. Thus the difference in standing crops of non-filamentous cells between the P1 and P3 was close to two orders of magnitude. Non-filamentous cells were not significantly different in abundance in the crop, mesenteron or mixed segment. Similarly in the hindgut there were no significant differences between the caecum, P4a, P4b and P5.

In contrast to non-filamentous cells, the total filament length increased from the crop to the mesenteron $(P<0.01)$ and from the mesenteron to the mixed segment $(P<0.005)$. Filaments decreased in the P1 to a standing crop not significantly different from that in the crop, but increased in the remaining posterior regions of the gut to be greater than in the 


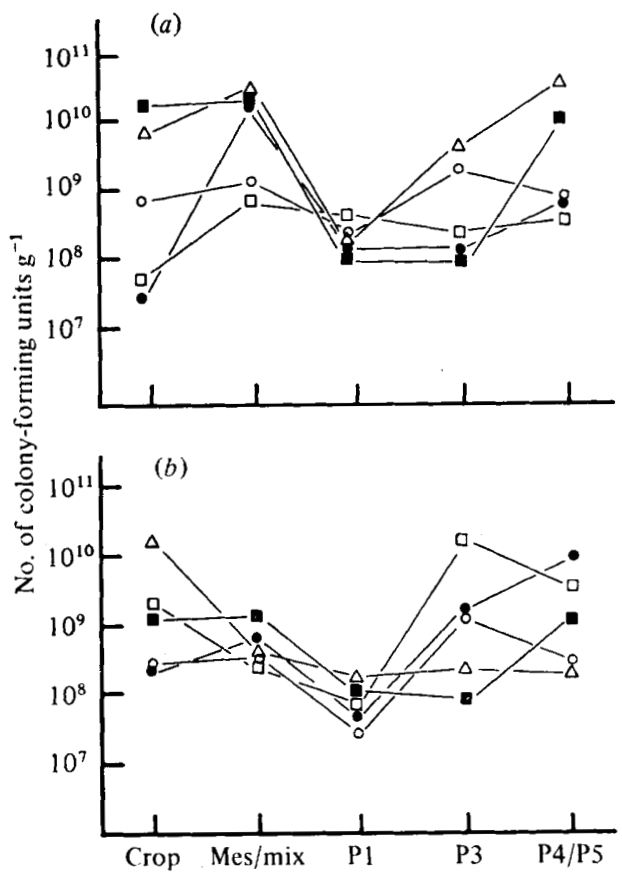

Fig. 3. Dilution counts of bacteria from gut homogenates plated on nutrient agar: (a) aerobic incubation; $(b)$ anaerobic incubation with reduced medium. In each case the results of five separate determinations are shown.

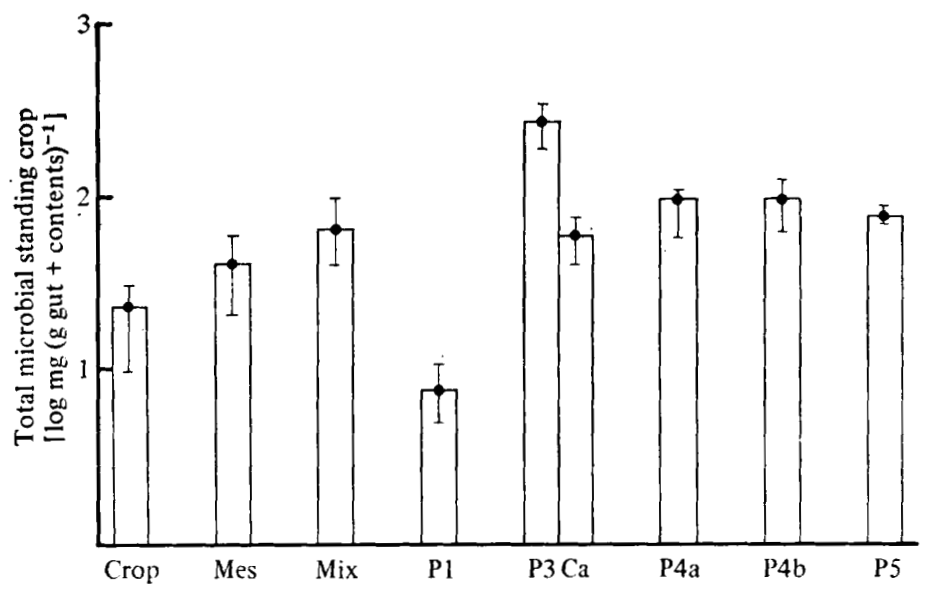

Fig. 4. Total standing crops of micro-organisms, determined by direct observation. Means and ranges of eight observations are shown.

P1 $(P<0.001)$. Standing crops of filaments were not significantly different in the P3, P4a $\mathrm{P} 4 \mathrm{~b}$ and $\mathrm{P} 5$, but were greater in all these than in the crop and mesenteron $(P<0.01)$. Filaments in the caecum were less abundant than in the P3, P4 or P5 $(P<0.001)$ but more abundant than in the P1 $(P<0.001)$.

Dilution plates incubated aerobically showed a significant reduction of counts in the P1 in comparison with the combined mesenteron and mixed segment $(P<0.01)$, but no significant differences between the crop, P1, P3 and combined P4/P5 (Fig. 3a). Facultative anaerobes showed a similar distribution with counts in the P1 significantly lower than in 
the crop, combined mesenteron and mixed segment and the combined P4/P5 $(P<0.01$, Fig. $3 b$ ). Comparison of aerobically and anaerobically incubated plates from the same dilution series showed no significant differences in the total counts of colony-forming units.

Figure 4 shows the total bacterial standing crops obtained by summation of the separate values for filamentous and non-filamentous forms. This shows a significant increase in the mixed segment compared with the crop $(P<0.001)$ followed by the expected drop in the $P 1$.The total standing crop in the P3 was significantly higher than in any other region of the gut $(P<0.001)$, while the caecum, P4a, P4b and P5 had total standing crops greater than those of the crop $(P<0 \cdot 001)$ but not significantly different from one another.

\section{Microscopy}

A preliminary examination of gut micro-organisms was carried out by electron microscopy to obtain evidence of functional associations with the host and to correlate with enumeration data. Since the foregut and hindgut of insects are lined by a chitinous cuticle which is the site of extensive microbial colonization in Lower Termites (Breznak \& Pankratz, 1977) the examination concentrated on associations with the gut wall or structures arising from it. In contrast to the foregut and hindgut, the wall of the mesenteron lacks a cuticle but is protected from direct contact with ingested materials by a chitinous peritrophic membrane secreted continuously by the epithelial cells (Chapman, 1969). It is generally believed that the membrane acts as a barrier to micro-organisms (Brandt et al., 1978) and since ingested materials pass into the hindgut with the enclosing membrane intact, colonization of the space between the peritrophic membrane and the epithelium of the mesenteron (i.e. the ectoperitrophic space) should not normally arise. In termites and other insects with an elongated hindgut the peritrophic membrane disintegrates rapidly after transit of the mesenteron thus permitting renewed contact between ingested materials and the gut wall.

The crop wall was found to be largely uncolonized (Fig. 5) although the attachment of filamentous organisms was occasionally seen. In the mesenteron a network of filaments was present in the ectoperitrophic space between the peritrophic membrane and the epithelium, completely surrounding the gut contents to form a continuous sheath extending from the posterior margin of the gizzard through the whole mesenteron and mixed segment (Fig. 6). In both the mesenteron and the mixed segment the filaments made intimate contact with the epithelium and ramified over the surface of the microvilli lining the gut lumen (Fig. 7). The cuticle of the hindgut component of the mixed segment was not colonized (Fig. 7). The filaments were never more than $0.5 \mu \mathrm{m}$ in diameter, infrequently branched, not obviously segmented or septate and clearly prokaryotic in ultrastructure. They were assumed to be actinomycetes (Williams et al., 1973; Slack \& Gerenscer, 1975) although sporing structures were not seen.

Fig. 5. Crop wall showing cuticular folds and the absence of microbial colonizers. Bar marker represents $10 \mu \mathrm{m}$.

Fig. 6. Transmission electron micrograph of the ectoperitrophic space of the mesenteron showing transverse sections of microbial filaments identified as actinomycetes: $\mathrm{C}$, mesenteric epithelial cell; PM, peritrophic membrane; S, mineral soil in gut lumen. Bar marker represents $2 \mu \mathrm{m}$.

Fig. 7. Portion of the mixed segment showing both mesenteric $(\mathrm{M})$ and proctodaeal $(\mathrm{P})$ components. Microbial filaments ramify over the surface of the mesenteron but the proctodaeal cuticle is uncolonized. Bar marker represents $5 \mu \mathrm{m}$.

Fig. 8. Wall of the $P 1$ with a ridge of cuticle $(R)$ and associated population of rods. Bar marker represents $1 \mu \mathrm{m}$.

Fig. 9. Wall of the P3 showing cuticular folds and the absence of attached microbial colonizers. Bar marker represents $1 \mu \mathrm{m}$. 

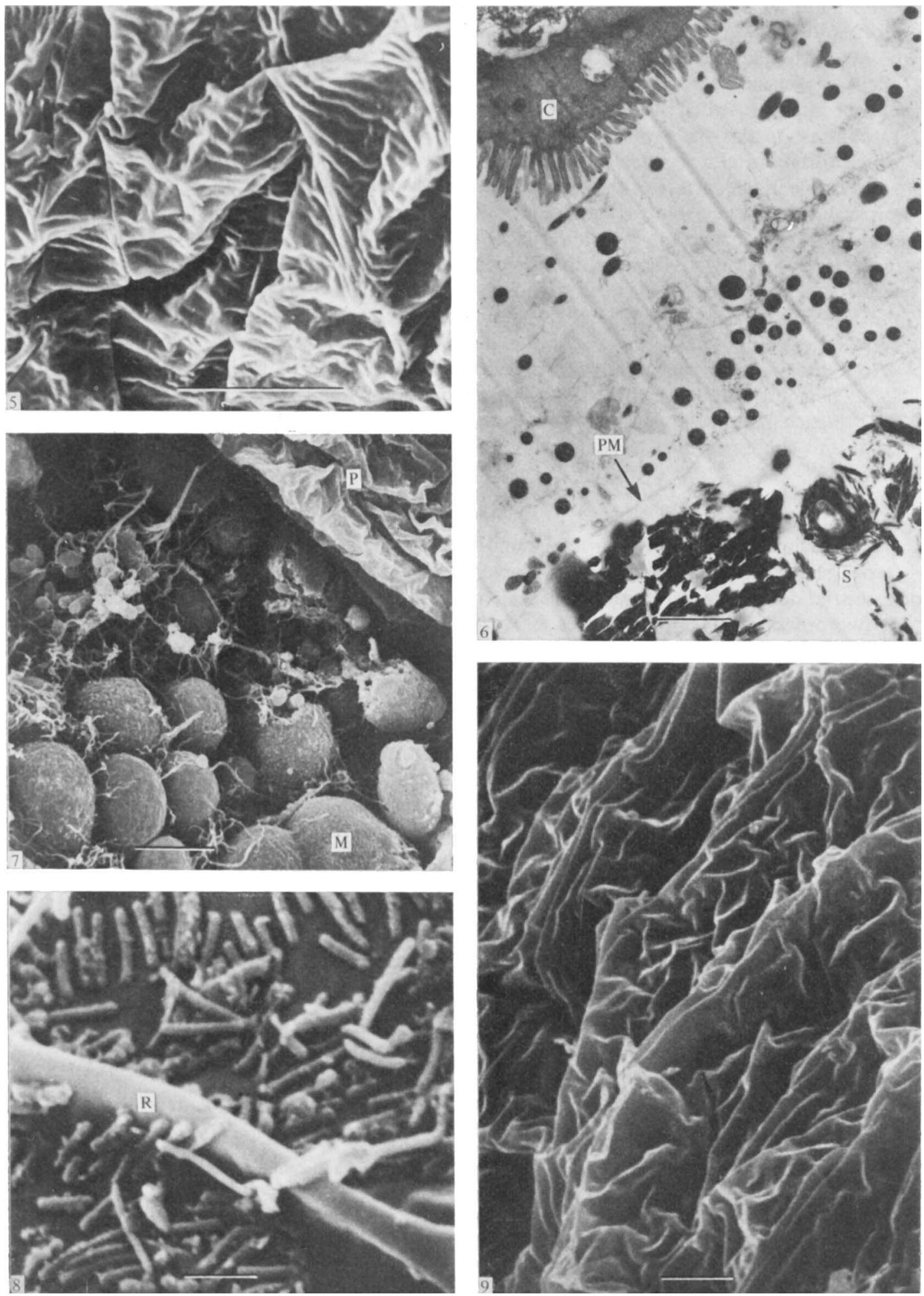
In the P1, the gut wall was colonized chiefly by non-filamentous bacteria in a variety of morphologies (Fig. 8). Colonization was uneven, areas of relatively dense clustering alternating with sparsely colonized or uncolonized zones. Despite the high standing crop of micro-organisms, the wall of the P3 was free of attached bacteria (Fig. 9), but examination of the contents revealed the presence of large numbers of slender rods and filaments (Fig. 10). In contrast to this the wall of the P4a was uniformly colonized by non-filamentous rods which formed a closely packed layer adhering to the cuticle (Fig. 11). A number of pits were visible in the surface of the cuticle itself, suggesting that absorption or secretion by the gut wall might be particularly active in this region. Overlying the rods in the P4a was a dense network of filaments which in places obscured the gut wall itself (Fig. 12). As in the mesenteron and mixed segment, the filaments in the P3 and P4a exhibited all the characteristics of actinomycetes, except obvious sporulation. Filaments were also abundant in the P4b but in contrast to the $\mathrm{P} 4 \mathrm{a}$ formed a novel association with greatly elongated cuticular spines to which they were attached (Fig. 13), creating in situ a complex matrix across the gut lumen through which ingested soil was filtered by peristalsis (Bignell et al., 1979). The gut wall between the spines was colonized by non-filamentous rods and showed the presence of cuticular pits (Fig. 14). The wall of the rectum (P5) was colonized by microorganisms similar to those adhering to the wall of the P4b.

\section{DISCUSSION}

Comparison of the total microbial standing crop of the rectum with that of the foregut (crop) showed a three- to fourfold increase. This is modest in comparison with some terrestrial detritus feeders ingesting leaves, where bacterial numbers were increased by one or two orders of magnitude (Reyes \& Tiedje, 1976; Anderson \& Bignell, 1980), and may imply that relatively little net change in population size accompanies the passage of soil through the alimentary canal. Thus, any effects on microbial metabolism and mineralization processes in soil arising from the activities of humivorous termites may be exerted chiefly through qualitative changes in bacterial populations. For example, filamentous organisms which are prominent components of the gut flora and develop contact with the gut wall in the mesenteron, mixed segment and posterior hindgut are also present in the rectal contents at a significantly higher standing crop than in freshly ingested soil. While the microbial population of faeces voided under natural conditions within the mound and foraging galleries cannot be readily determined, the absence of filament attachments in the rectum makes it probable that the organisms observed and enumerated in the rectal contents are incorporated into faecal pellets.

It is unclear at present whether the increases of actinomycetes and other micro-organisms in ingested soil are attributable to growth by the indigenous soil flora or represent losses from symbiotic populations unique to the host. However, the attachment of actinomycetes

Fig. 10. Dense population of elongated rods mixed with some microbial filaments in the mineral contents of the P3. Bar marker represents $0.5 \mu \mathrm{m}$.

Fig. 11. Wall of the P4a showing cuticular pits (arrowed) and adherent non-filamentous bacteria. Bar marker represents $1 \mu \mathrm{m}$.

Fig. 12. Mat of actinomycete filaments overlaying the cuticle and adherent non-filamentous bacteria in the P4a. Bar marker represents $1 \mu \mathrm{m}$.

Fig. 13. Low magnification view of the P4b opened by a longitudinal incision to show elongated cuticular spines and adherent masses of actinomycete filaments (arrowed). The longitudinal axis is perpendicular to the bar marker, which represents $50 \mu \mathrm{m}$.

Fig. 14. Base of a cuticular spine showing articulation with the gut wall and ramification of actinomycete filaments in the lumen. Non-filamentous rods are attached to the cuticle of the gut wall between the spines (arrowed). Bar marker represents $10 \mu \mathrm{m}$. 

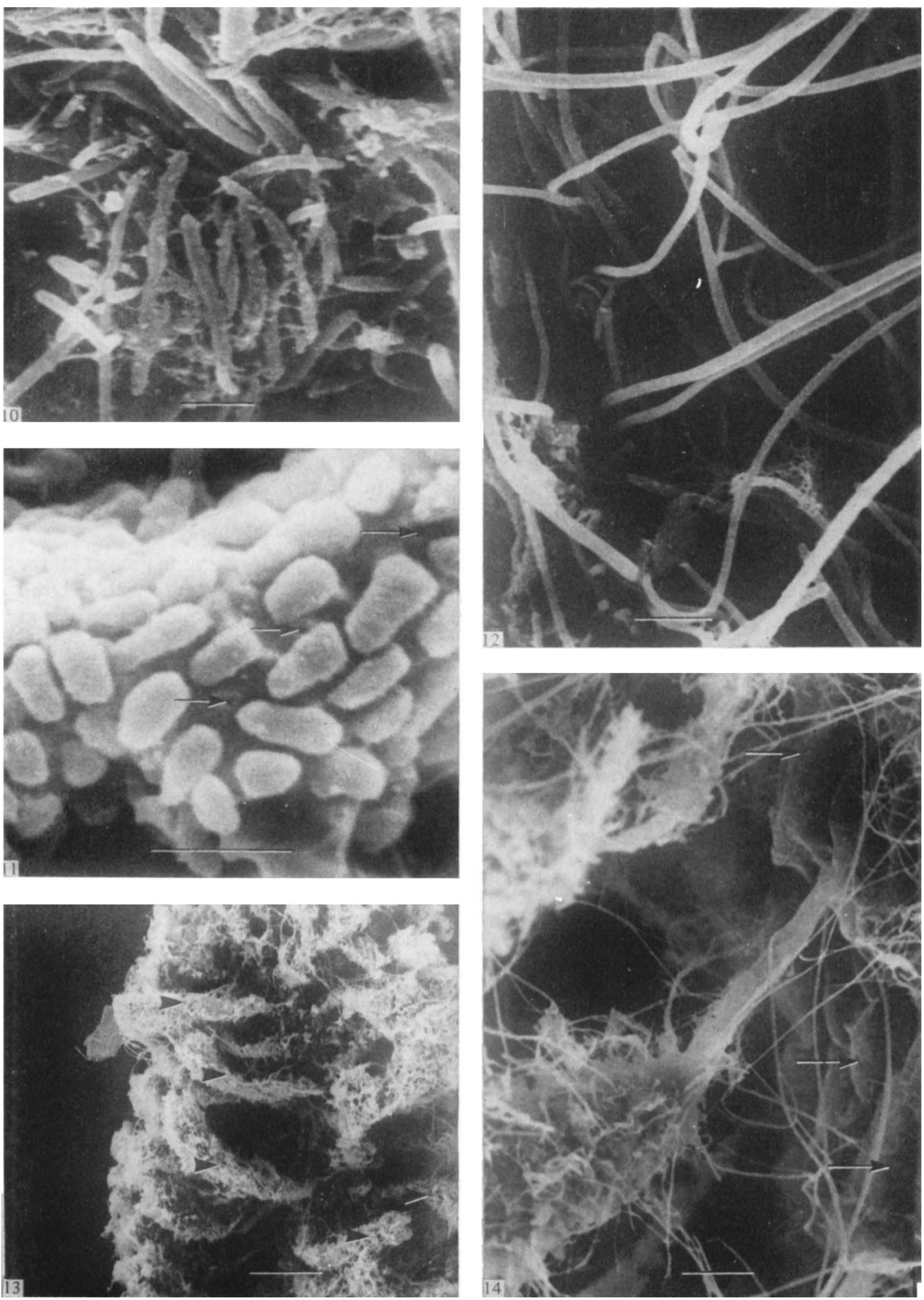
to cuticular spines in the $\mathrm{P} 4 \mathrm{~b}$ and to the gut wall in the ectoperitrophic space of the mesenteron and the mixed segment, together with the dense colonization of the wall of the P4a by both filamentous and non-filamentous organisms, may be cited as evidence that permanent or semi-permanent associations are formed between the host and components of its gut flora. The large population of non-filamentous rods in the P3, contributing to the exceptionally high microbial standing crop in this region, would also appear to be permanent since non-filamentous bacteria were less abundant in the remaining posterior regions of the hindgut.

The mesenteron is usually considered the major site of digestive enzyme secretion and of absorption in insects lacking intestinal symbionts (House, 1974). Since no reduction in microbial standing crop was demonstrated in the mesenteron of Procubitermes it seems unlikely that the termites utilized the organic resources of bacterial tissues directly. However, both standing crops and colony-forming units were significantly reduced in the $\mathrm{Pl}$, indicating that lysis of organisms was occurring in this region. It cannot be ruled out that some of the organic materials thus made available were utilized by the insect. We have established that a sharp rise in $\mathrm{pH}$ of the gut contents occurs in the mixed segment and $\mathrm{P} 1$, reaching 10 to 11 in the latter (D. E. Bignell \& J. M. Anderson, unpublished results), then decreasing progressively in the $\mathrm{P} 3, \mathrm{P} 4 \mathrm{a}$ and $\mathrm{P} 4 \mathrm{~b}$ to reach a value close to neutrality in the rectum. It is conceivable that the high $\mathrm{pH}$ of the $\mathrm{Pl}$ contributes to conditions which result in lysis and that symbiont populations in the posterior hindgut are thereby protected from competitive interactions with ingested soil flora.

We thank Dr T. G. Wood of the Overseas Development Ministry Termite Project for the supply of termites and the British Museum (Natural History) for assistance with electron microscopy. The work was funded by grant GR3/3145 of the Natural Environment Research Council to J. M.A.

\section{REFERENCES}

Anderson, J. M. \& Bignell, D. E. (1980). Bacteria in the food, gut and faeces of the pill millipede Glomeris marginata. Soil Biology and Biochemistry (in the Press).

Bignell, D. E., Oskarsson, H. \& Anderson, J. M. (1979). Association of actinomycete-like bacteria with soil-feeding termites. Applied and Environmental Microbiology 37, 339-342.

BlOODGOOD, R. A., Miller, K. R., Fitzharris, T. P. \& MCINTOSH, J. R. (1974). The ultrastructure of Pyrsonympha and its associated micro-organisms. Journal of Morphology 143, 77-106.

Brandt, C. R., Adang, M. J. \& Spence, K. D. (1978). The peritrophic membrane: ultrastructural analysis and function as a mechanical barrier to microbial infection in Orgyia pseudotsugata. Journal of Invertebrate Pathology 32, 12-24.

Breznak, J. A. \& Pankratz, H. S. (1977). In situ morphology of the gut microbiota of wood-eating termites (Reticulitermes flavipes Kollar and Coptotermes formosanus Shiraki). Applied and Environmental Microbiology 33, 406-426.

Breznak, J. A., Brill, W. J., Mertins, J. W. \& Coppell, H. C. (1973). Nitrogen fixation in termites. Nature, London 244, 577-580.

Brooks, M. A. (1963). The micro-organisms of healthy insects. In Insect Pathology, An Advanced Treatise, pp. 215-250. Edited by E. A. Steinhaus. New York: Academic Press.
Chapman, R. F. (1969). The Insects-Structure and Function, 1st edn. New York: American Elsevier.

Eutick, M. L., O'Brien, R. W. \& Slaytor, M. (1978). Bacteria from the gut of Australian termites. Applied and Environmental Microbiology 35, 823-828.

Grassé, P.-P. \& NoIrot, C. (1959). L'évolution de la symbiose chez les Isoptères. Experientia 15, 365-372.

Hanlon, R. D. G. \& Anderson, J. M. (1980). The influence of macroarthropod feeding activities on fungi and bacteria in decomposing oak leaves. Soil Biology and Biochemistry (in the Press).

Honigberg, B. M. (1970). Protozoa associated with termites and their role in digestion. In Biology of Termites, vol. 2, pp. 1-36. Edited by K. Krishna \& F. M. Weesner. New York: Academic Press.

House, H. E. (1974). Digestion. In The Physiology' of Insecta, 2nd edn, vol. 5, pp. 63-117. Edited by M. Rockstein. New York: Academic Press.

Hungate, R. E. (1955). Mutualistic intestinal protozoa. Biochemistry and Physiology of Protozoa 2, 159-199.

Jones, P. C. T. \& Mollison, J. E. (1948). A technique for the quantitative estimation of soil microorganisms. Journal of General Microbiology 2, 54-69. 
Kovoor, J. (1959). Anatomie du tractus intestinal dans le genre Microcerotermes (Silvestri), (Isoptera, Termitidae). Bulletin de la Société zoologique de France 84, 445-457.

Kovoor, J. (1969). Anatomie comparée du tube digestif des termites II. Sous-famille des Nasutitermitinae. Insectes sociaux 16, 195-234.

LEE, K. E. \& Wood, T. G. (1971). Termites and Soils. London: Academic Press.

Martin, M. M. \& Martin, J. S. (1978). Cellulose digestion in the midgut of the fungus-growing termite Macrotermes natalensis: the role of acquired digestive enzymes. Science 199, 14531455 .

NoIrot, C. \& Kovoor, J. (1958). Anatomie comparée du tube digestif des termites I. Sous-famille des Termitinae. Insectes sociaux 5, 439-471.

Noirot, C. \& Noirot-Timothée, C. (1969). The digestive system. In Biology of Termites, vol. 1, pp. 49-88. Edited by K. Krishna \& M. Weesner. New York: Academic Press.

OLSEN, F. C. W. (1950). Quantitative estimates of filamentous algae. Transactions of the American Microscopical Society 59, 272-279.

Parkinson, D., Gray, T. R. G. \& Williams, S. T. (1971). Methods for Studying the Ecology of Soil Micro-organisms. Oxford: Blackwell.
Potrikus, C. J. \& Breznak, J. A. (1977). Nitrogenfixing Enterobacter agglomerans isolated from guts of wood-eating termites. Applied and Environmental Microbiology 33, 392-399.

Reyes, U. G. \& TIEDJE, J. M. (1976). Ecology of the gut microbiota of Tracheoniscus rathkei (Crustacea, Isopoda). Pedobiologia 16, 67-74.

RoHrMANN, G. F. (1978). The origin, structure and nutritional importance of the comb in two species of Macrotermitinae (Insecta, Isoptera). Pedobiologia 18, 89-98.

Slack, J. M. \& Gerenscer, M. A. (1975). Actinomyces, Filamentous Bacteria: Biology and Pathogenicity. Minneapolis: Burgess Publishing Co.

Sokal, R. R. \& Rohlf, F. J. (1969). Biometry. San Francisco: W. H. Freeman \& Co.

Williams, S. T., Sharples, G. P. \& Bradshaw, R. M. (1973). The fine structure of the Actinomycetales. In Actinomycetales, Characteristics and Practical Importance, pp. 113-130. Edited by G. Sykes \& F. A. Skinner. London: Academic Press.

WooD, T. G. (1976). The role of termites (Isoptera) in decomposition processes. In The Role of Terrestrial and Aquatic Organisms in Decomposition Processes. Edited by J. M. Anderson \& A. Macfadyen. Oxford: Blackwell. 